\title{
A New Minimally Invasive Approach for Treatment of Middle and Distal- third Humeral Shaft Fractures
}

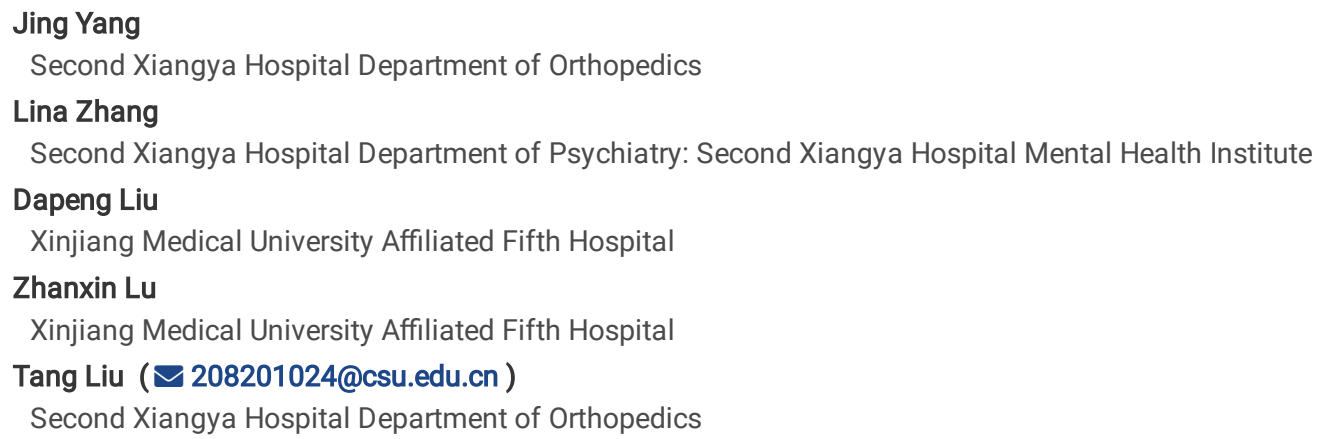

Research article

Keywords: Humeral shaft fractures, MIPO, Anteromedial, Radial nerve, Minimally-Invasive

Posted Date: May 28th, 2021

DOI: https://doi.org/10.21203/rs.3.rs-555692/v1

License: @ (i) This work is licensed under a Creative Commons Attribution 4.0 International License. Read Full License 


\section{Abstract}

Purpose: To evaluate the feasibility and safety of a new minimally-invasive surgical approach-anteromedial minimally-invasive plate osteosynthesis (MIPO) in the treatment of middle and distal-third segment humeral shaft fractures.

Methods: From November 2016 to March 2020, 14 patients (8 males and 6 females) with middle and distal-third segment humeral shaft fracture who were treated surgically by one surgeon of our department were retrospectively evaluated. Four fractures were type $A 1$, tow fractures type $A 2$, four fractures type A3 and four fractures type B1. In the surgical procedure, 11 fractures were treated with anterolateral MIPO approach, while three fractures used the anterolateral + lateral MIPO approach. Patient's age averaged 48 years (range, 25-81).

Results: Average follow-up time, months: 21.7, (range 12 to 36 months). QuickDASH score at final follow-up averaged 2.5 points (range, $0-4.5)$, The constant score averaged 88.5 points (range, 80-100). All fractures there were no nerve injuries, infections, and Other severe complications occurred.

Conclusion: The anteromedial approach MIPO technique has the advantages of less trauma, less bleeding, low risk of nerve injury and high rate of fracture healing. It is one of the most effective methods for the treatment of middle and middle-distal humeral shaft fractures. Our study provided a new approach for the treatment of middle and distal-third segment Humeral shaft fractures.

\section{Introduction}

Humeral shaft fractures account for $2-4 \%$ of all fractures ${ }^{1}$, yet at present, there is no clear gold standard for the treatment of humeral shaft fracture ${ }^{2 ;}{ }^{3}$. Although most humeral shaft fractures can be treated nonoperatively, surgical treatment leads to better fracture reduction and early functional exercise 4 . However, dissection of soft tissue during open reduction can affect the blood supply to the fracture, increasing the risk of fracture nonunion, incision infection, and iatrogenic nerve injury. With the mature application of minimally-invasive plate osteosynthesis (MIPO) in the treatment of fractures, MIPO has been used as an alternative and has achieved good results ${ }^{5}$. Some authors reported using the anterolateral minimally-invasive approach, and the incidence of distal incision iatrogenic radial nerve palsy remained high ${ }^{6}$. The iatrogenic injury of the radial nerve is related to its special anatomical location and locus ${ }^{1}$. The purpose of our study was to report our experience in the treatment of middle and distal humerus fractures with an anteromedial approach to MIPO, to evaluate the feasibility and safety of the surgical approach, and to evaluate the postoperative function of the upper limb.

\section{Materials And Methods}

\section{General information}

The study was reviewed and approved by the institutional ethics board of the hospital, all patients gave informed consent and agreed to participate in our study. We retrospectively evaluated 14 patients treated between November 2016 and February 2020 at our hospital, comprised eight males and six females, between the ages of 25 and 81 (mean age $47.79 \pm 18.61$ ). There were 11 cases on the left side and three cases on the right side. AO type: A1.2:3; A1.3: one case; A3.2: four cases; A2.2: two cases; B1.2: one case; B1.3: three cases. All patients had a history of trauma. There was no vessel or nerve injury in preoperative patients. (Table 1).

Table 1

Patient data, AO/OTA Classification and Associated Injuries

\begin{tabular}{|c|c|c|c|c|c|c|}
\hline Case & Age (years) & Gender & Side Injured & Cause & AO/OTA classification & Associated Injuries \\
\hline 1 & 63 & Male & Left & Fall & A1.2 & None \\
\hline 2 & 46 & Female & Left & Road traffic accident & A1.2 & None \\
\hline 3 & 38 & Male & Left & Road traffic accident & A3.2 & None \\
\hline 4 & 51 & Male & Left & Road traffic accident & A1.2 & None \\
\hline 5 & 45 & Male & Left & Fall & A3.2 & None \\
\hline 6 & 26 & Male & Left & Road traffic accident & A3.2 & None \\
\hline 7 & 64 & Male & Left & Fall & A2.2 & None \\
\hline 8 & 63 & Female & Left & Fall & A2.2 & None \\
\hline 9 & 74 & Female & Right & Fall & B1.2 & None \\
\hline 10 & 25 & Female & Right & Rolled in machine & B1.3 & None \\
\hline 11 & 35 & Female & Left & Road traffic accident & B1.3 & None \\
\hline 12 & 81 & Male & Left & Fall & A3.2 & None \\
\hline 13 & 31 & Female & Right & Fall & B1.3 & None \\
\hline 14 & 27 & Male & Left & Rolled in machine & A1.3 & None \\
\hline
\end{tabular}

Page 2/9 


\section{Surgical technique}

Three patients. were treated with the anteromedial + anterolateral MIPO technique and fixed with locking compression plate (LCP) + multi-directional locking screw system (MDLS). 11 patients were used a minimally invasive antero-medial approach and fixed with LCP. Patients were administered brachial plexus nerve tissue anesthesia, then positioned with the trunk supine, the arm and shoulder abducted 90 degrees, and the forearm in complete supination. The medial epicondyle was first palpated and the incision was begun $1 \mathrm{~cm}$ in front of the medial epicondyle. To determine the space between the biceps and triceps brachii, $3-4 \mathrm{~cm}$ of skin was cut proximally along the biceps groove. The basilar vein and medial forearm cutaneous nerve were identified and protected, the brachialis muscle fascia was incised, and the anteromedial surface of the distal humerus was exposed, The LCP was placed on the skin to determine the location of the proximal humerus incision, and the proximal incision was determined by palpating the space between the proximal biceps and the medial margin of the deltoid. After determining the insertion point of the pectoralis major tendon, the long head tendon of the biceps brachii was pulled medially and the dissection was continued downward to the medial surface of the proximal shaft of the humerus (Fig. 1). To achieve full exposure, part of the pectoralis major insertion could be removed and subcutaneous MIPO tunnels created, connecting the distal and proximal incisions. The steel plate was inserted from the distal end to the proximal, and the position of the steel plate was adjusted by locking the drill bushings at the distal and proximal ends. The fracture was then reduced with the aid of fluoroscopy. Once the reduction was satisfactory, a lag screw was drilled proximally to help position the fracture reduction, the shoulder and elbow were moved, no impact was confirmed, and the proximal and distal locking screws were drilled sequentially, using at least three proximal screws (Fig. 2A-D). If the distal end was near the medial condyle, a single cortical locking screw was selected for fixation, and the incision was sutured without an indwelling drainage tube. A typical case is shown in (Fig. $3 A-D)$. Of the 14 patients, three patients (A3.2, B1.3, A1.3) were treated with the anteromedial + anterolateral MIPO technique and fixed with LCP + MDLS . Passive movement of the shoulder and elbow joints was then used to examine the stability of the bone plate structure

\section{Postoperative management}

Postoperatively, a forearm sling was used for 2 weeks, and shoulder and elbow joints were passively moved. After 2 weeks, the shoulder and elbow joints were gradually moved actively. After X-ray imaging showed the presence of a bone connection at the fracture end, strength exercises were performed. None of the patients included in this study had radial nerve injury. X-ray examination was performed 3 days after surgery, and outpatient examination was performed 1 and 3 months after surgery. X-ray examination was performed every 6 months thereafter to observe fracture healing. QuickDASH score and Constant score were given at the last follow-up to evaluate the postoperative recovery effect.

\section{Observation indicators}

Incision length $(\mathrm{cm})$, intraoperative blood loss ( $\mathrm{mL})$, intraoperative X-ray fluoroscopy (times), operation time (minutes), hospital stay (days), fracture healing time (months), follow-up time (months), QuickDASH score amd Constant score at last follow-up were all evaluated and compared.

\section{Results}

Median operation time was 110 minutes (range, 90-160 minutes), and the number of intraoperative fluoroscopy images 20 times (range, $15-27$ times), with no intraoperative complications or postoperative deep wound infections reported.

The mean follow-up of all 14 patients was 21.7 months (range 12 to 36 months). All surgeries were uneventful and no intraoperative complications occurred. 24 months post-operation, after fracture healing one patient removed the plate. DASH score at final follow-up averaged 2.5 points (range, $0-$ 4.5), The constant score averaged 99.6 points (range, $80-100)$; the incision length $(7.79 \pm 2.39 \mathrm{~cm})$, intraoperative blood loss ( $96.07 \pm 14.96 \mathrm{~mL}$ ), hospital stay ( $6.29 \pm 1.49$ days) and fracture healing time (14.94 \pm 0.99 weeks). The number of intraoperative fluoroscopy images (20.07 \pm 3.22$)$. (Table 2). 
Table 2

The Results of patients with humeral shaft fractures treated with MIPO

\begin{tabular}{|c|c|c|c|c|c|c|c|c|c|c|c|}
\hline $\begin{array}{l}\text { Patient } \\
\text { Number }\end{array}$ & $\begin{array}{l}\text { Surgical } \\
\text { Delay } \\
\text { Post } \\
\text { Injury } \\
\text { (Days) }\end{array}$ & $\begin{array}{l}\text { Plate } \\
\text { type }\end{array}$ & $\begin{array}{l}\text { Incision } \\
\text { Length(cm) }\end{array}$ & $\begin{array}{l}\text { Bleeding } \\
\text { volume(ml) }\end{array}$ & $\begin{array}{l}\text { Fluoroscopy } \\
\text { times }\end{array}$ & $\begin{array}{l}\text { operative } \\
\text { time } \\
\text { (min) }\end{array}$ & $\begin{array}{l}\text { HSD } \\
\text { (days) }\end{array}$ & $\begin{array}{l}\text { BH } \\
\text { (weeks) }\end{array}$ & $\begin{array}{l}\text { FFU } \\
\text { (months) }\end{array}$ & $\begin{array}{l}\text { QuickDASH } \\
\text { score }\end{array}$ & $\begin{array}{l}\text { Constant } \\
\text { score }\end{array}$ \\
\hline 1 & 3 & LCP & 6 & 90 & 22 & 110 & 8 & 15.2 & 24 & 0.0 & 90 \\
\hline 2 & 3 & LCP & 8 & 100 & 18 & 98 & 5 & 14.31 & 18 & 4.5 & 85 \\
\hline 3 & 2 & LCP & 7 & 95 & 19 & 90 & 4 & 14.2 & 29 & 2.3 & 86 \\
\hline 4 & 3 & LCP & 6 & 110 & 27 & 95 & 5 & 15.3 & 34 & 2.3 & 90 \\
\hline 5 & 2 & LCP & 6 & 85 & 15 & 105 & 6 & 16.2 & 27 & 3.2 & 80 \\
\hline 6 & 2 & $\begin{array}{l}\text { LCP+ } \\
\text { MDLS }\end{array}$ & 10 & 80 & 16 & 140 & 5 & 15.3 & 24 & 2.3 & 86 \\
\hline 7 & 3 & LCP & 6 & 80 & 20 & 100 & 7 & 14.3 & 16 & 0.0 & 100 \\
\hline 8 & 3 & LCP & 6 & 90 & 25 & 113 & 6 & 15.4 & 16 & 3.2 & 88 \\
\hline 9 & 4 & LCP & 7 & 110 & 19 & 105 & 8 & 16.4 & 14 & 2.2 & 90 \\
\hline 10 & 2 & LCP & 8 & 95 & 21 & 95 & 5 & 15.3 & 14 & 4.5 & 80 \\
\hline 11 & 2 & LCP & 8 & 75 & 19 & 90 & 6 & 14 & 12 & 3.5 & 90 \\
\hline 12 & 2 & LCP & 6 & 110 & 18 & 102 & 8 & 16.2 & 12 & 3.2 & 85 \\
\hline 13 & 3 & $\begin{array}{l}\text { LCP + } \\
\text { MDLS }\end{array}$ & 11 & 95 & 20 & 145 & 6 & 13.0 & 28 & 2.2 & 95 \\
\hline 14 & 4 & $\begin{array}{l}\text { LCP + } \\
\text { MDLS }\end{array}$ & 14 & 130 & 22 & 160 & 9 & 14 & 36 & 2.0 & 95 \\
\hline
\end{tabular}

\section{Discussion}

Although ORIF is the main surgical method for the treatment of humeral shaft fracture, the exposure of the fracture site by open reduction damages the blood supply of the humerus, which may affect fracture healing. The rate of fracture nonunion reported in the literature is $6-15 \%{ }^{7}$. The traditional anterolateral approach may cause iatrogenic injury to the radial nerve, and iatrogenic radial nerve paralysis occurs in $0-12 \%$ of cases ${ }^{7}$. Extensive intraoperative exposure of soft tissue in ORIF also increases the incidence of deep postoperative infection of the incision ${ }^{8}$. In recent years, scholars have applied MIPO technology in the treatment of humeral shaft fracture and achieved good results. The MIPO technique uses small incisions far away from the fracture site to avoid direct exposure to the fracture, theoretically improving the healing rate and reducing the risk of infection through the incision ${ }^{9}$. An LCP is mostly used in a MIPO operation, which does not need to be completely fitted to the bone surface ${ }^{10 ; 11}$. Use of a locking screw reduces the pressure of the plate on the bone, protects the periosteal blood supply, and is conducive to fracture healing.

The MIPO group required a shorter incision length, suffered less blood loss, and had a shorter postoperative hospitalization time and shorter fracture healing time, but on the other hand this technique involved an increase in the amount of radiation exposure during the operation, leading to a certain amount of radiation damage to physicians and patients ${ }^{12}$. Some studies have reported on a MIPO technique for middle and distal humeral shaft fracture by placing the plate using anterior approach for the proximal incision and lateral approach for the distal incision combined with exploration of the radial nerve through an oblique incision, however, an iatrogenic radial nerve palsy occurred in three of seven patients ${ }^{13}$.

Regarding postoperative recovery, according to the results of this study, the MIPO group with a markedly shortened postoperative recovery time ${ }^{14}$. Our results showed that MIPO can restore limb length, correct deformity, restore the axis angle, requires a smaller incision, and leaves smaller and less disfiguring scars. MIPO conforms to the principle of biological treatment of fracture, promotes stability and reconstruction of the local blood supply, reduces the incidences of infection or delayed union, and promotes recovery of patients' shoulder joint function. In this retrospective study, all patients had healed fractures.

The aim of our study was to validate the efficacy and safety of the MIPO anteromedial approach for the treatment of middle and distal humeral shaft fractures by combining the advantages of the anteromedial approach and the MIPO technique. Anatomically, the anteromedial approach to MIPO is a safe and effective approach for the treatment of middle-distal humeral shaft fractures ${ }^{15}$. The pronator teres and brachialis muscles were pulled laterally, protecting the median nerve and brachial artery. The mean distance from the distal incision to the median nerve was $2.34 \mathrm{~cm}(95 \% \mathrm{Cl}, 2.18-$ 
$2.50 \mathrm{~cm})^{16}$. Radial nerve palsy is known to be a major complication of the anterior and anterolateral MIPO technique, and the incidence of radial nerve palsy with the posterior MIPO technique is $5.4 \%{ }^{17}$. The lateral approach to the distal humerus in MIPO inevitably affects the radial nerve, while the anteromedial approach avoids the risk of radial nerve injury.

Ulnar nerve injury is also a concern with the anteromedial approach to MIPO of the distal humerus ${ }^{18}$, as the ulnar nerve runs near the apex of the epicondyle within the humerus, and the distal plate is located lateral to the ulnar nerve in the treatment of a fracture in the middle and lower part of the humerus. The distal screw is very close to the ulnar nerve and the space available for the plate is narrow. In our experience, in distal humerus fractures, we prefer to use a multi-directional locking screw system (MDLS) for distal locking screw monocortical fixation, and if necessary, a plate can be added laterally to stiffen the fixation ${ }^{16}$ (Fig. 4A-D).

A study by Cañada-Oya et al. ${ }^{16}$ concluded that a proximal plate may affect the long head tendon of the biceps brachii. Based on our clinical experience, a proximal plate pulls the biceps tendon medially to the patient but the plate can be placed on the deltoid insertion and part of the deltoid insertion can be removed if necessary (Fig. 5). According to the long-term patient follow-up, if the plate was located below the long head bond of the biceps, there was no discomfort associated with movement of the shoulder joint, so it was not necessary to choose a shorter plate. If the plate is short and is located below the belly of the biceps brachii, proximal screw fixation will be difficult due to the greater soft tissue coverage ${ }^{16}$.

The advantages of this new anteromedial minimally-invasive approach include the ability to place the external fixator on the lateral side of the humerus during the operation to maintain intraoperative reduction without compromising the operation ${ }^{16}$. In clinical practice, we prefer to use a lag screw to pull the humerus proximally to the plate and reduce the fracture with the plate. In cases of complex fractures of the distal humerus, we can use an anterolateral approach to assist plate fixation ${ }^{19 ;} 20$.

Based on our study, the anteromedial MIPO approach may be an alternative for middle and distal humerus fractures. If the fracture extends distally and the fixation is unstable, we recommend a lateral approach to assist fixation by the MIPO technique ${ }^{21 ; 22}$. This approach may also increase the stability of fixation, especially in cases of severe osteoporosis, periprosthetic fractures, and pathological fractures requiring biplanar fixation. A dual plate can be used in combination with an anterolateral or lateral approach to reconstruct the medial and lateral columns of the distal humerus while preserving blood supply to the surrounding soft tissues and hastening fracture healing.

A limitation of our study, a case series, is the absence of a formal control group of patients who were operated upon using anterior, anterolateral and posterior approaches. The sample size of this study is small, so more medical records and long-term follow-up studies are still needed to further verify this conclusion.

\section{Conclusion}

Based on our clinical practice studies, the anteromedial approach to MIPO allows exposure of the proximal and distal incisions without exposing the nerves and vessels. However, it is difficult to insert a screw between the distal and proximal incisions. This method can be used as an option for extraarticular fractures of the middle and distal humerus shaft with less trauma and is a safe and feasible surgical method. Excellent outcomes were achieved for anteromedial approach MIPO technique. Our study provided a new Minimally invasive approach for treatment of middle and distal-third segment Humeral shaft fractures.

\section{Abbreviations}

MIPO Minimally Invasive Plate Osteosynthesis

LCP Locking Compression Plate

MDLS Multi Directional Locking Screw System

\section{Declarations}

\section{Level of Evidence}

Level IV, Case Series. Treatment Study.

\section{Ethics approval and consent to participate:}

This retrospective chart review study involving human participants was in accordance with the ethical standards of the institutional and national research committee and with the 1964 Helsinki Declaration and its later amendments or comparable ethical standards. The study was reviewed and approved by the institutional ethics board of the Fifth Affiliated Hospital of Xinjiang Medical University.

All authors certify that the methods were carried out in accordance with relevant guidelines and regulations.

All authors certify that the study was reviewed and approved by the Fifth Affiliated Hospital of Xinjiang Medical University. 


\section{Consent for publication}

Written informed consent for publication was obtained from all participants.

\section{Availability of data and materials}

The data and materials during the current study are available from the corresponding author on reasonable request.

\section{Competing interests}

The authors have no relevant financial or non-financial interests to disclose.

The authors have no conflicts of interest to declare that are relevant to the content of this article.

All authors certify that they have no affiliations with or involvement in any organization or entity with any financial interest or non-financial interest in the subject matter or materials discussed in this manuscript.

The authors have no financial or proprietary interests in any material discussed in this article.

\section{Funding:}

This study had no financial support.

\section{Authors' contribution}

All authors contributed to the study conception and design.

Conceptualization: Jing Yang and Tang Liu. Methodology: Dapeng Liu and Zhanxin Lu. Formal analysis investigation: Lina Zhan. Writing - original draft preparation: Jing Yang. Writing - review and editing: Jing Yang and Tang Liu.

All authors commented on previous versions of the manuscript.

All authors read and approved the final manuscript.

\section{Acknowledgements}

Not applicable

\section{Informed consent:}

All authors certify that the patients gave informed consent and agreed to participate in our study.

All authors certify that all patients provided a signed informed consent prior to the operation.

\section{References}

1. Updegrove GF, Mourad W, Abboud JA. Humeral shaft fractures. J Shoulder Elbow Surg. 2018;27:e87-97.

2. Ouyang $\mathrm{H}$, Xiong $\mathrm{J}$, Xiang $\mathrm{P}$, et al. Plate versus intramedullary nail fixation in the treatment of humeral shaft fractures: an updated meta-analysis. $\mathrm{J}$ Shoulder Elbow Surg. 2013;22:387-95.

3. Gosler MW, Testroote M, Morrenhof JW, et al. Surgical versus non-surgical interventions for treating humeral shaft fractures in adults. Cochrane Database Syst Rev. 2012;1:CD008832.

4. Allende C, Vanoli F, Gentile L, et al. Minimally invasive plate osteosynthesis in humerus nonunion after intramedullary nailing. Int Orthop. 2018;42:2685-9.

5. Seo JB, Heo K, Yang JH, et al. Clinical outcomes of dual 3.5-mm locking compression plate fixation for humeral shaft fractures: Comparison with single 4.5-mm locking compression plate fixation. J Orthop Surg (Hong Kong). 2019;27:2309499019839608.

6. An Z, Zeng B, He X, et al. Plating osteosynthesis of mid-distal humeral shaft fractures: minimally invasive versus conventional open reduction technique. Int Orthop. 2010;34:131-5.

7. Jiang R, Luo CF, Zeng BF, et al. Minimally invasive plating for complex humeral shaft fractures. Arch Orthop Trauma Surg. 2007;127:531-5.

8. Rämö L, Sumrein BO, Lepola V, et al. 2020. Effect of Surgery vs Functional Bracing on Functional Outcome Among Patients With Closed Displaced Humeral Shaft Fractures. Jama 323.

9. Lode I, Nordviste V, Erichsen JL, et al. Operative versus nonoperative treatment of humeral shaft fractures: a systematic review and meta-analysis. J Shoulder Elbow Surg. 2020;29:2495-504.

10. Lu S, Wu J, Xu S, et al. Medial approach to treat humeral mid-shaft fractures: a retrospective study. J Orthop Surg Res. 2016;11:32. 
11. Lotzien S, Hoberg C, Rausch V, et al. 2019. Open reduction and internal fixation of humeral midshaft fractures: anterior versus posterior plate fixation. BMC Musculoskeletal Disorders 20.

12. Meinberg EG, Agel J, Roberts CS, et al. Fracture and Dislocation Classification Compendium-2018. J Orthop Trauma. 2018;32(Suppl 1):1-170.

13. Zogbi DR, Terrivel AM, Mouraria GG, et al. Fracture of distal humerus: MIPO technique with visualization of the radial nerve. Acta Ortop Bras. 2014;22:300-3.

14. Liskutin T, Summers H, Lack W, et al. Surgical Technique: Anterolateral Approach to the Humerus. J Orthop Trauma. 2018;32(Suppl 1):6-7.

15. Nowak LL, Dehghan N, McKee MD, et al. Plate fixation for management of humerus fractures. Injury. 2018;49:33-8.

16. Cañada-Oya H, Cañada-Oya S, Zarzuela-Jiménez C, et al. New, Minimally Invasive, Anteromedial-Distal Approach for Plate Osteosynthesis of DistalThird Humeral Shaft Fractures. 5: JBJS Open Access; 2020.

17. Balam KM, Zahrany AS. Posterior percutaneous plating of the humerus. Eur J Orthop Surg Traumatol. 2014;24:763-8.

18. Buranaphatthana T, Apivatthakakul T, Apivatthakakul V. Anteromedial minimally invasive plate osteosynthesis (MIPO) for distal third humeral shaft fractures - Is it possible?: A cadaveric study. Injury. 2019;50:1166-74.

19. Lee T, Yoon J. Newly designed minimally invasive plating of a humerus shaft fracture; a different introduction of the plate. Int Orthop. 2016;40:2597-602.

20. Lee HJ, Oh CW, Oh JK, et al. Minimally invasive plate osteosynthesis for humeral shaft fracture: a reproducible technique with the assistance of an external fixator. Arch Orthop Trauma Surg. 2013;133:649-57.

21. Lau TW, Leung F, Chan CF, et al. Minimally invasive plate osteosynthesis in the treatment of proximal humeral fracture. Int Orthop. 2007;31:657-64.

22. Jiamton C, Ratreprasatsuk N, Jarayabhand R, et al. The safety and feasibility of minimal invasive plate osteosynthesis (MIPO) of the posterior aspect of the humerus: A cadaveric study. Clin Anat. 2019;32:176-82.

\section{Figures}
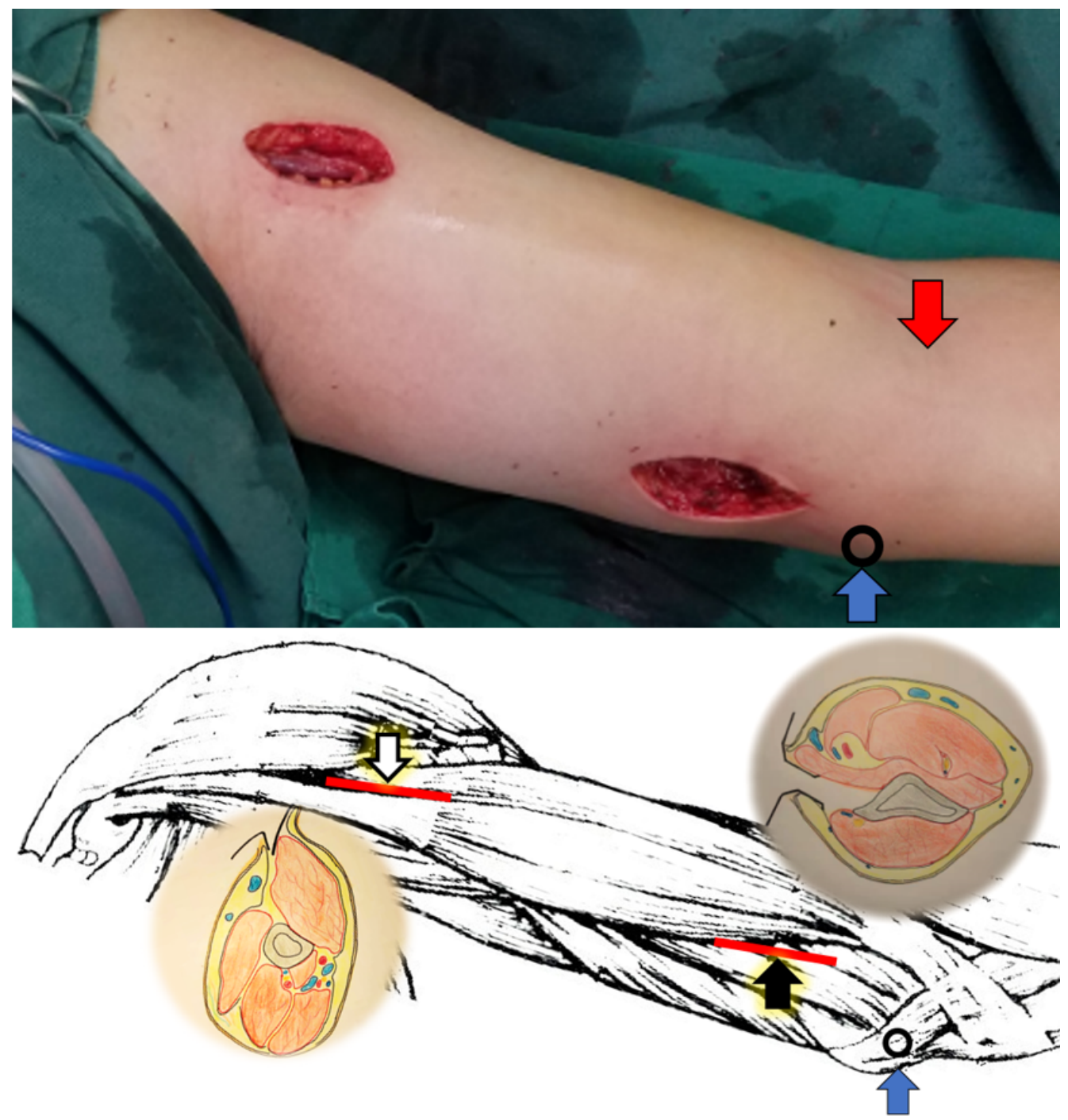

Figure 1 
The proximal incision (white arrow in artist illustration); the distal incision (black arrow in artist illustration) is made along the medial margin of the biceps and proximal to the elbow flexion crease (red arrow); Proximal and distal incisions of the left arm diagrams of the plane of dissection; (blue arrow: the medial epicondyle)
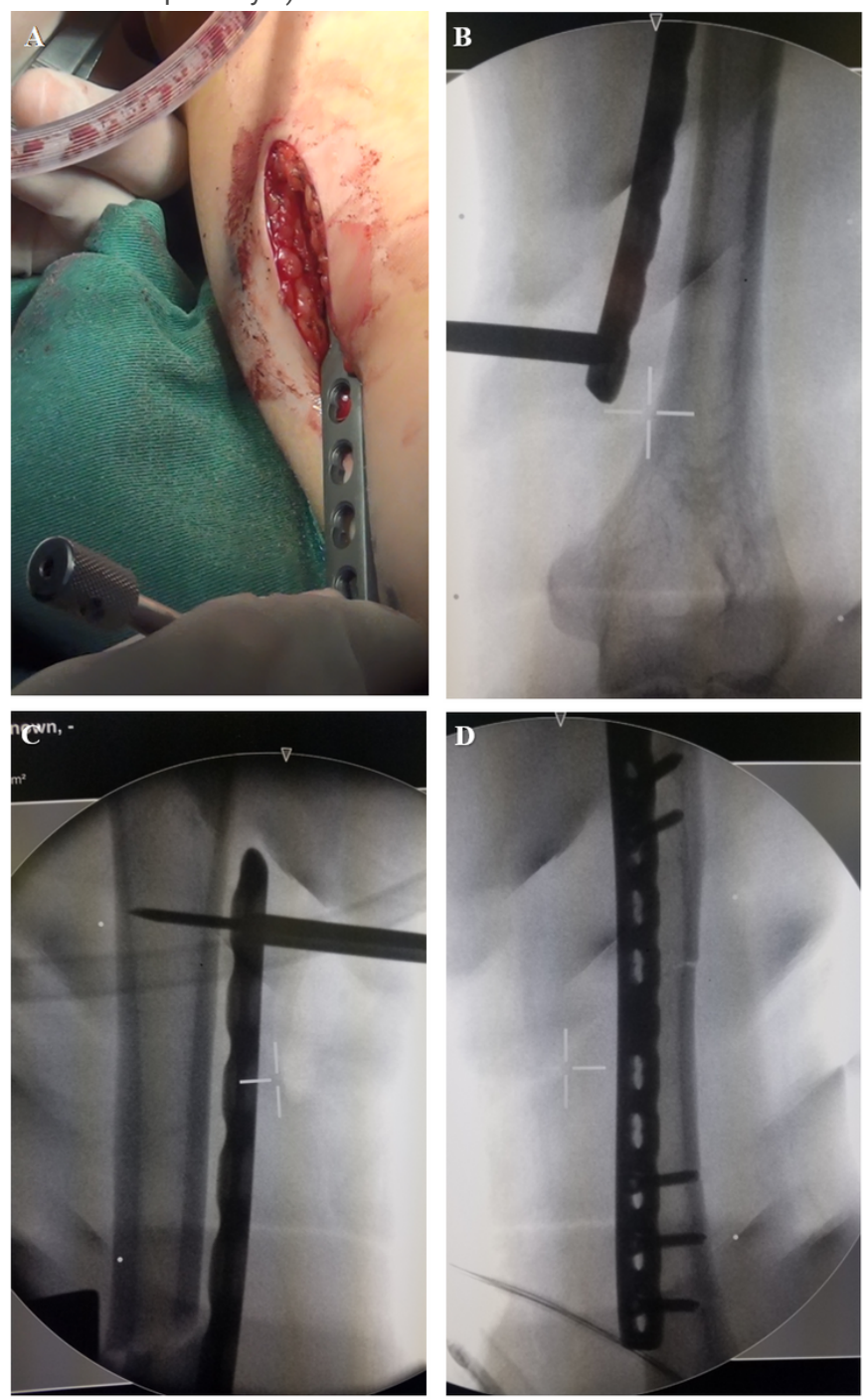

\section{Figure 2}

(A) the plate was inserted in the distal incisions. (B) Intraoperative X-ray fluoroscopy was used to observe the reduction process. (C) Intraoperative X-ray fluoroscopy was used to observe the reduction process. (D) Intraoperative fluoroscopy after locking plate fixation

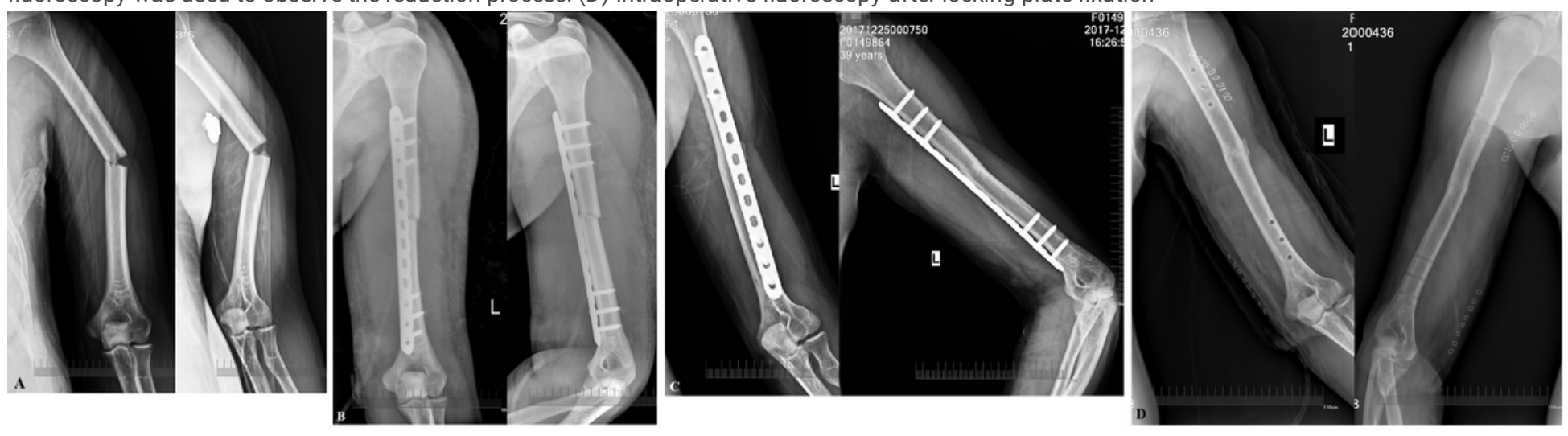

Figure 3

(A) A 38-year-old man (case 3) Road traffic accident and sustained a middle fracture of the left humeral shaft (B) was treated with the anteromedial MIPO technique. (C) 12 months after surgery, the bone was clinically united in anatomical alignment (D) 24 months after surgery, in accordance with the requirements of the patient, the internal fixation was removed 

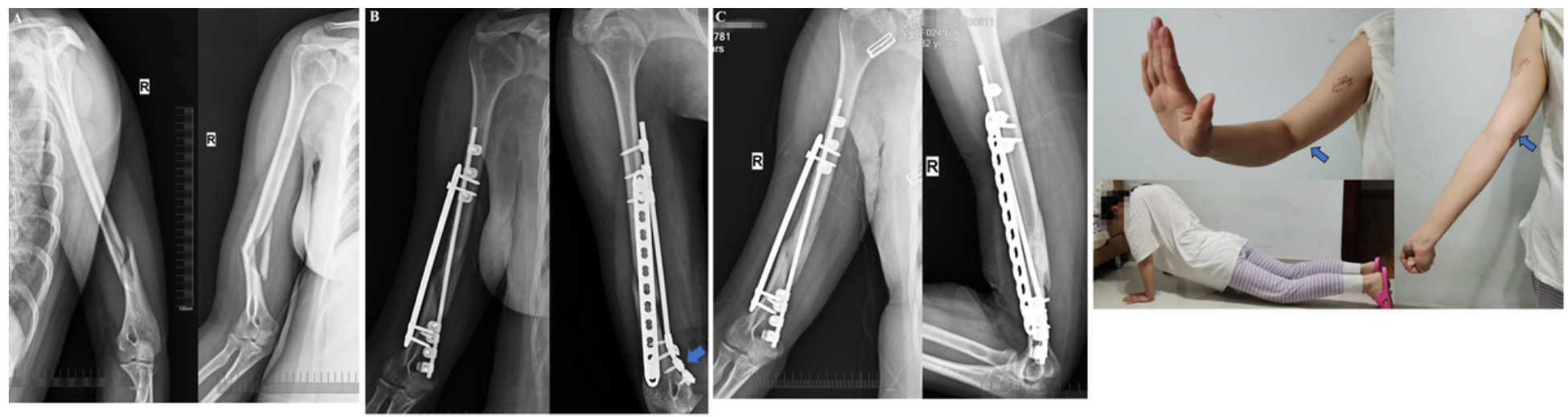

Figure 4

(A) A 31-year-old woman (case 13) fell and sustained a distal third fracture of the right humeral shaft. (B) were treated with the anteromedial + anterolateral MIPO technique and fixed with LCP+MDLS (arrow: fixation of a single miniplate with multi-directional locking screw) (C) Six months after surgery, the bone was clinically united in anatomical alignment. (D) 28 months after surgery, with full recovery of function. (arrow: well-hidden scar at the elbow)

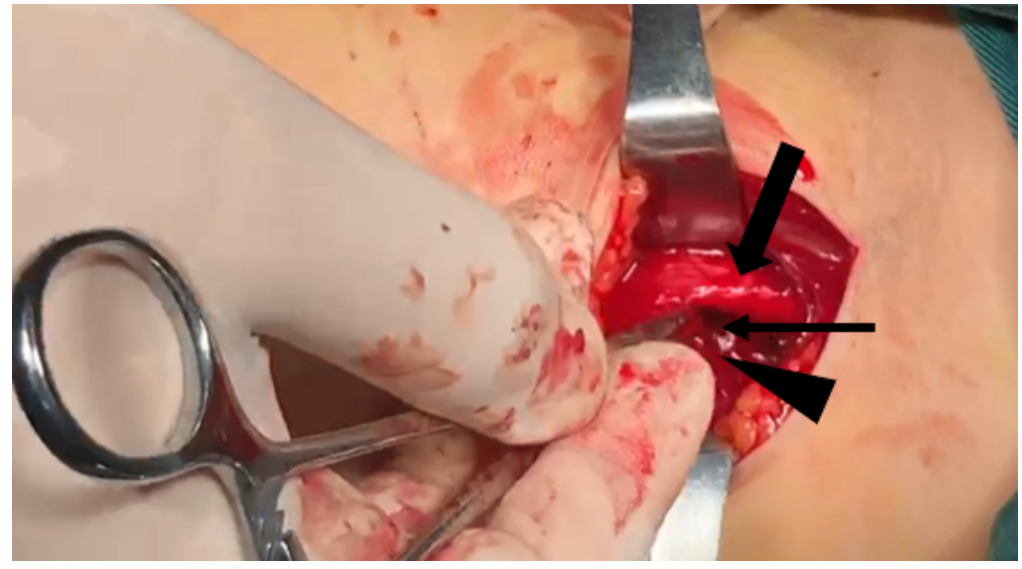

Figure 5

Intra-operative photograph showing the proximal incision (triangular arrow head), the insertion of the pectoralis major (broad arrow); the long head of the brachii tendon (slim arrow) during the anteromedial approach to a humeral shaft fracture 